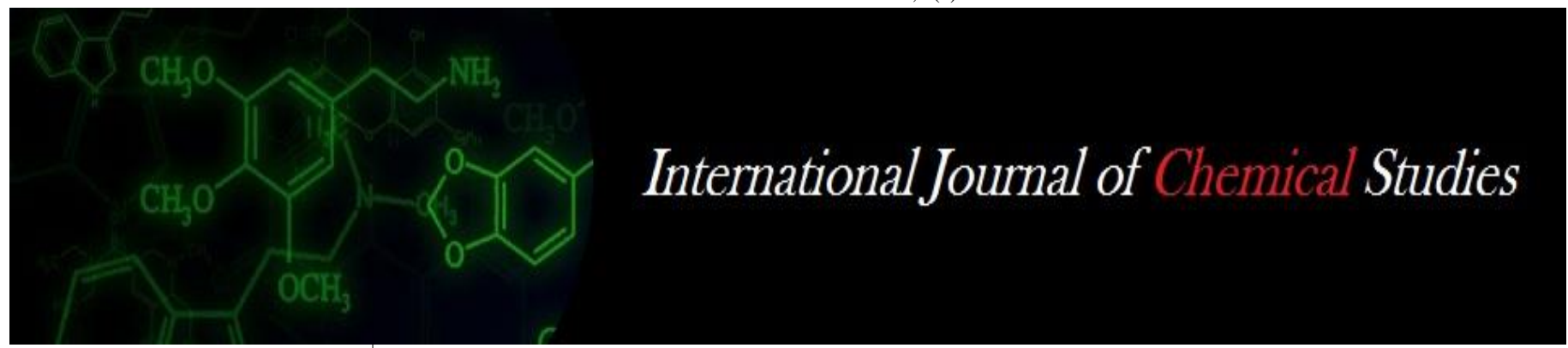

P-ISSN: 2349-8528

E-ISSN: 2321-4902

www.chemijournal.com

IJCS 2020; 8(2): 2488-2490

(C) 2020 IJCS

Received: 10-01-2020

Accepted: 12-02-2020

\section{SP Monalisa}

Department of Crop Physiology, Institute of Agricultural

Sciences, Siksha 'O' Anusandhan

University, SOA (DU),

Bhubaneswar, Odisha, India
Corresponding Author: SP Monalisa

Department of Crop Physiology, Institute of Agricultural

Sciences, Siksha 'O' Anusandhan

University, SOA (DU),

Bhubaneswar, Odisha, India

\title{
Effect of growing season on the oil content percentage of five sesamum genotypes in six developmental stages
}

\section{SP Monalisa}

DOI: https://doi.org/10.22271/chemi.2020.v8.i2al.9123

\begin{abstract}
In the current investigation, the oil content percentage of five sesamum genotypes (Uma, Amrit, Nirmal, CUMS-17, Prachi) in six developmental stages (7 DAA, 14 DAA, 21 DAA, 28 DAA, 35 DAA and 42 DAA ) were estimated in three growing seasons (summer, kharif and rabi). The field and lab experiments were carried out in Seed Science and Technology Department, OUAT, Bhubaneswar. The oil content percentage increased consistently up to 42 DAA but there was no significance difference between 35 DAA (maturity stage) and 42 DAA. Prachi and CUMS-17 (46.6\%, 44.9\%) recorded the highest oil content percentage in seeds throughout the period of seed development, respective at maturity stage and Uma was the lowest (41.6\%). By comparing the three growing seasons, the kharif harvest seeds recorded the highest oil content (44.9\%) followed by summer (43.5\%) and rabi (42.6\%) at maturity stage.
\end{abstract}

Keywords: DAA, maturity stage, kharif, rabi, summer

\section{Introduction}

Sesame is frequently known as Til and is used as edible oilseeds in India. It is cultivated in the country since antiquity. It is carrying about 21.5 per cent protein, 60.8 per cent fat, 8.9 per cent carbohydrate and 3.4 per cent ash (Nanda \& Agrawal, 2009) ${ }^{[3]}$. Sesame seeds contain sesamolin, sesamin and sesamol like a lot of natural anti-oxidant health benefiting compounds. Sesamin also contain Vitamin B-complex. Niacin is found abundantly in sesamin. It reduces LDL- cholesterol levels in blood. It enhances GABA activity in the brain which helps reducing anxiety and neurosis. 73 per cent of the sesamum oil is used for edible purposes, 8.3 per cent for hydrogenation and 4.2 per cent for industrial purposes in manufacture of paints, pharmaceuticals and insecticides. This is also used in soap, cosmetic and skin care industries. It is very stable, anti-bacterial, anti-viral, anti-fungal and anti-oxidant. Though this oil is cholesterol free, it is used in health food industries. Seed is the cardinal unit of agriculture which gives maximum return in crop production to the farmer. Production, distribution and timely supply of quality seeds are therefore, inevitable to boost the production because no agriculture practice can improve the productivity beyond the limit set by the seed. Seed quality depends on a larger number of factors such as environmental, biotic, physical and physiological. Among several factors, the main problem for low yield is the non-availability of quality seeds. Quality seeds are important input in crop production. Among various factors affecting quality seed production, the influence of growing season appears significant in expression of various morphological, physiological and biochemical traits which ultimately determines the productivity of crop and sowing quality of seed (Nema, 1991) ${ }^{[4]}$. Therefore, selection of appropriate growing season is important while planning for seed production. High seed quality in terms of viability and vigour and biochemical parameters are essential factors which determine faster and better seedling development and crop establishment in field for receiving higher seed yield besides its better quality. Seeds become worthless if they fail to germinate and give high result (Heydecker et al., 1975) ${ }^{[2]}$. This study was undertaken to investigate the effect of growing seasons on the oil content percentage of five sesamum genotypes in six developmental stages. 


\section{Materials and Methods \\ Collection of sample}

Seeds of five varieties/genotypes of sesame (Uma, Amrit, Nirmal, CUMS-17 and Prachi) were used in this experiment and the Breeder seeds were collected from AICRP on sesame, OUAT. Bhubaneswar. The seed crop of each treatment and replication were grown in kharif, rabi and summer, and seeds of remaining twenty capsules, harvested at each developmental stage for each replication and genotype, were separated, dried and used for oil extraction purposes.

\section{Extraction and collection of oil content:}

Fats are the fatty acid esters of glycerol. Fat as liquid is called oil. Seeds of sesamum contain oil as reserve food material for the embryo. Oil from a known quantity of sesamum seed is extracted by using petroleum ether. After that, it is then distilled off completely, then dried properly, and oil weighted and the oil percentage is calculated.

\section{Materials required}

Petroleum ether $\left(40-160{ }^{\circ} \mathrm{C}\right)$, Whatman No. 2 Filter paper, Absorbant cotton, Soxhlet apparatus.

\section{Procedure}

1. First fold a piece of filter paper in such a way that it properly holds the seed meal. After that, wrap around a second filter paper which is left open at the top like a thimble. A piece of cotton wool is placed at the top to evenly distribute the solvent as it drops on the sample during extraction.

2. Sample packet place in the butt tubes of the Soxhlet extraction apparatus.

3. Extraction of oil mixed with petroleum ether $(150$ drops/min) for $6 \mathrm{hr}$ without interruption by gentle heating.

4. Allow to cool the extraction flask and then dismantle the extraction flask. Evaporate the ether by using a steam or water-bath until no odour of ether remains. Cool it at room temperature.

5. The dirt or moisture which is placed outside the flask remove carefully and then weigh the flask. Repeat the heating until constant weight is calculated.

\section{Calculation of oil content}

Oil $(\%)$ in ground sample $=$ Weight of oil $(\mathrm{g}) /$ Weight of sample $(\mathrm{g}) \times 100$

\section{Results}

Changes in oil content with progress in seed development of individual varieties in different growing seasons could be revealed through [Table-1, 2, 3, 4]. The oil content of developing seeds increased consistently up to 42 DAA but there was no significant difference between 35DAA and 42DAA. Irrespective of growing seasons, Prachi and CUMS17 recorded the highest oil percentage in seeds throughout the period of seed development, possessing $46.6 \%$ and $44.9 \%$, respectively at maturity stage. In contrast, Uma consistently recorded the lowest value for this trait throughout the period of seed development with $41.6 \%$ at maturity stage. The comparative performance of sesamum varieties in respect of this parameter indicated considerable variation among the growing seasons. The kharif seeds had the highest oil content (44.9\%) followed by the summer $(43.5 \%)$ and rabi $(42.6 \%)$ seeds at maturity stage.
Table 1: Changes in oil content (\%) at different maturity stages in five sesamum varieties under summer season

\begin{tabular}{|c|c|c|c|c|c|c|}
\hline Variety & \multicolumn{6}{|c|}{ Days after anthesis (DAA) } \\
\hline & $\mathbf{7}$ & $\mathbf{1 4}$ & $\mathbf{2 1}$ & $\mathbf{2 8}$ & $\mathbf{3 5}$ & $\mathbf{4 2}$ \\
\hline UMA & 20.5 & 30.7 & 35.9 & 40.3 & 41.2 & 41.2 \\
\hline AMRIT & 21.3 & 31.0 & 37.4 & 41.7 & 42.0 & 42.0 \\
\hline NIRMAL & 21.7 & 31.4 & 38.1 & 42.1 & 42.7 & 42.7 \\
\hline CUMS-17 & 22.7 & 32.4 & 38.8 & 44.3 & 45.4 & 45.4 \\
\hline PRACHI & 24.1 & 34.9 & 40.8 & 45.2 & 46.0 & 46.0 \\
\hline MEAN & 22.0 & 32.1 & 38.2 & 42.7 & 43.4 & 43.5 \\
\hline SEm $( \pm)$ & 0.59 & 0.80 & 0.98 & 1.08 & 1.13 & 1.13 \\
\hline CD $(0.05)$ & 1.82 & 2.48 & 3.01 & 3.33 & 3.47 & 3.47 \\
\hline
\end{tabular}

Table 2: Changes in oil content (\%) at different maturity stages in five sesamum varieties under kharif season

\begin{tabular}{|c|c|c|c|c|c|c|}
\hline Variety & \multicolumn{7}{|c|}{ Days after anthesis (DAA) } \\
\hline & $\mathbf{7}$ & $\mathbf{1 4}$ & $\mathbf{2 1}$ & $\mathbf{2 8}$ & $\mathbf{3 5}$ & $\mathbf{4 2}$ \\
\hline UMA & 24.8 & 34.6 & 36.5 & 40.5 & 43.0 & 43.0 \\
\hline AMRIT & 25.8 & 35.3 & 37.6 & 42.1 & 43.3 & 43.3 \\
\hline NIRMAL & 27.0 & 36.1 & 38.9 & 42.3 & 44.2 & 44.3 \\
\hline CUMS-17 & 27.2 & 37.0 & 39.8 & 45.0 & 45.5 & 45.5 \\
\hline PRACHI & 28.2 & 39.4 & 42.1 & 45.6 & 48.2 & 48.2 \\
\hline MEAN & 26.6 & 36.5 & 39.0 & 43.1 & 44.9 & 44.9 \\
\hline SEm $( \pm)$ & 0.71 & 1.02 & 0.98 & 1.08 & 1.15 & 1.14 \\
\hline CD $(0.05)$ & 2.19 & 3.13 & 3.02 & 3.34 & 3.54 & 3.52 \\
\hline
\end{tabular}

Table 3: Changes in oil content (\%) at different maturity stages in five sesamum varieties under rabi season

\begin{tabular}{|c|c|c|c|c|c|c|}
\hline Variety & \multicolumn{7}{|c|}{ Days after anthesis (DAA) } \\
\hline & $\mathbf{7}$ & $\mathbf{1 4}$ & $\mathbf{2 1}$ & $\mathbf{2 8}$ & $\mathbf{3 5}$ & $\mathbf{4 2}$ \\
\hline Uma & 19.3 & 30.5 & 35.2 & 38.9 & 40.6 & 40.7 \\
\hline Amrit & 19.9 & 31.0 & 35.7 & 41.1 & 41.3 & 41.3 \\
\hline Nirmal & 20.1 & 31.2 & 36.2 & 41.6 & 41.7 & 41.7 \\
\hline Cums-17 & 20.6 & 32.6 & 38.2 & 42.7 & 43.6 & 43.6 \\
\hline Prachi & 22.2 & 34.8 & 39.9 & 44.4 & 45.6 & 45.6 \\
\hline Mean & 20.4 & 32.0 & 37.1 & 41.7 & 42.6 & 42.6 \\
\hline SEm( \pm$)$ & 0.52 & 0.82 & 0.95 & 1.04 & 1.12 & 1.12 \\
\hline CD $(0.05)$ & 1.61 & 2.52 & 2.91 & 3.22 & 3.44 & 3.44 \\
\hline
\end{tabular}

Table 4: Overall changes in oil content (\%) at different maturity stages in response to varieties and growing seasons

\begin{tabular}{|c|c|c|c|c|c|c|}
\hline \multirow{2}{*}{ Variety/Season } & \multicolumn{7}{|c|}{ Days after anthesis (DAA) } \\
\cline { 2 - 7 } & $\mathbf{7}$ & $\mathbf{1 4}$ & $\mathbf{2 1}$ & $\mathbf{2 8}$ & $\mathbf{3 5}$ & $\mathbf{4 2}$ \\
\hline Variety & & & & & & \\
\hline Uma & 21.5 & 31.9 & 35.9 & 39.9 & 41.6 & 41.6 \\
\hline Amrit & 22.3 & 32.4 & 36.9 & 41.6 & 42.2 & 42.2 \\
\hline Nirmal & 22.9 & 32.9 & 37.7 & 42.0 & 42.9 & 42.9 \\
\hline Cums-17 & 23.5 & 34.0 & 38.9 & 44.0 & 44.8 & 44.9 \\
\hline Prachi & 24.8 & 36.4 & 40.9 & 45.1 & 46.6 & 46.6 \\
\hline SEm $( \pm)$ & 0.35 & 0.51 & 0.56 & 0.62 & 0.65 & 0.65 \\
\hline CD $(0.05)$ & 1.02 & 1.47 & 1.60 & 1.77 & 1.87 & 1.87 \\
\hline Season & & & & & & \\
\hline Summer & 22.0 & 32.1 & 38.2 & 42.7 & 43.4 & 43.5 \\
\hline Kharif & 26.6 & 36.5 & 39.0 & 43.1 & 44.8 & 44.9 \\
\hline Rabi & 20.4 & 32.0 & 37.1 & 41.7 & 42.6 & 42.6 \\
\hline Overall mean & 23.0 & 33.5 & 38.1 & 42.5 & 43.6 & 43.7 \\
\hline SEm $( \pm)$ & 0.33 & 0.50 & 0.36 & 0.60 & 0.59 & 0.58 \\
\hline CD $(0.05)$ & 0.95 & 1.43 & 1.02 & 1.71 & 1.68 & 1.68 \\
\hline
\end{tabular}

\section{Discussion}

In the present study, oil content of seed was estimated at weekly intervals from the day of anthesis in all the five varieties in all the three seasons. The results indicated a rapid increase at the initial stage up to two weeks followed by a steady increase up to $35 \mathrm{DAA}$ after which there was either no change or little rise in the oil content of seeds. The pattern of 
change was sigmoid as was observed in dry matter accumulation. Although all the varieties showed similar trend of change, they differed in the magnitude with the highest value found in Prachi followed by CUMS -17 . The seed oil content of these two varieties at maturity stage was $46.6 \%$ and $44.9 \%$, respectively. Besides this, the lowest oil content $(41.6 \%)$ in mature seed was observed in Uma. Seeds produced in different seasons also differed significantly in their oil content. The kharif seeds possessed higher oil followed by those produced in summer and rabi in that order. The better plant growth in kharif and summer seasons favoured better photosynthesis thereby higher oil content in seeds. The result of the investigation is in agreement with those of Awasthi and Pathak (1993) ${ }^{[1]}$ and Paramjit et al., (1995) ${ }^{[5]}$ who reported similar pattern of accumulation and genotypic variability in seed oil content of mustard.

\section{Conclusion}

Accumulation of soluble protein and oil in developing seeds increased gradually with progress of seed maturity and attained the highest values around 35 DAA. The pattern of enhancement was sigmoid as was observed in dry matter accumulation in developing seeds. Among the varieties, Prachi and CUMS-17 and among the seasons, seeds produced in kharif, exhibited higher values in respect of these two biochemical traits. The activity of alpha-amylase and dehydrogenase in developing seeds also followed similar trend of enhancement in respect to pattern of increase, genotypic and seasonal variations.

\section{References}

1. Awasthi PK, Pathak RK. Changes in oil content and fatty acid composition in developing seeds of high erucic mustard (Brassica juncea) varieties. Agrochemica. 1993; 37(1, 2):77-85.

2. Heydecker W, Hiiggins J, Turner YJ. Invigoration of seeds. Seed Sci. Technol. 1975; 3:881-888.

3. Nanda JS, Agrawal PK. Botany of Field Crops, Kalyani Publishers., Ludhiana. 2009; 1:287-292

4. Nema BK, SK Rai MK, Nema, Baghel BS. Effect of GA3 on growth of Khirni seedling (Abstract) National seminar on optimization of productivity and utilization of sapota, Navasari, 1991, 50

5. Paramjit S, Satwinder K, Gupta VP, Kaur S, Singh P. Combining ability analysis for oil yield and its components in Brassica napus L. Cruciferae Newsletter. 1995; 22:67-69. 